\title{
PLEITESÍA SOCIAL HACIA EL MOBILIARIO ESPAÑOL: HISTORIOGRAFÍA Y DIVERGENCIAS EN LOS MODELOS DE COMUNICACIÓN A TRAVÉS DE LAS EXPOSICIONES TEMPORALES
}

\section{TO THE SPANISH SOCIAL HOMAGE FURNITURE: HISTORIOGRAPHY AND DIFFERENCES IN THE MODELS OF COMMUNICATION THROUGH TEMPORARY EXHIBITIONS}

\author{
Antonio Rafael Fernández Paradas ${ }^{1}$. Universidad de Granada. España. \\ antonioparadas@ugr.es
}

\section{RESUMEN}

A diferencia de países como Francia e Inglaterra, en España han sido mínimas las exposiciones monográficas dedicadas a mueble antiguo español. Los escasos ejemplos nacionales destacan por su singular trascendencia y repercusión en la propia Historia de nuestros muebles. Nos interesa aquí profundizar en la dimensión social de las mismas, así como cuantificar su número y las interrelaciones que entre ellas se han producido, dado que nos permiten trazar una evolución de los lenguajes expositivos utilizados como medios de comunicación.

PALABRAS CLAVE: mueble, mobiliario español, exposiciones temporales, historiografía, modelos de comunicación.

\section{ABSTRACT}

Unlike countries such as France and England, in Spain the monographic exhibitions dedicated to the Spanish furniture have been minimal. The limited national examples stand out for their singular transcendency and repercussion in the History of our furniture. We are interested in emphasize the social dimension of them, as well as in quantifying his number and the interrelationships made between them.

KEY WORDS: furniture, Spanish furniture, temporary exhibitions, historiography. catalogue, exhibition.

Cómo citar el artículo:

Fernández Paradas, A. R. (2016). Pleitesía social hacia el mobiliario español: Historiografía y divergencias en los modelos de comunicación a través de exposiciones temporales. Revista de Ciencias de la Comunicación e Información, 21(1), 45-56. doi: http://doi.org/10.35742/rcci.2016.21(1).45-56

\footnotetext{
1 Antonio Rafael Fernández Paradas: Profesor Ayudante Doctor. Facultad de Ciencias de la Educación. Universidad de Granada. España.
} 


\section{INTRODUCCIÓN}

La verdad es que todo tipo de investigación se ha disparado, por decirlo de algún modo, en nuestros tiempos y la bibliografía se ha multiplicado asombrosamente en los últimos quince años. Y dentro de este panorama no es de extrañar que hayan proliferado también los estudios sobre mobiliario y aparecido visiones de conjunto totales o parciales de su sabido interés, amenazándonos otros con inminencia. Creemos que esta exposición contribuirá a aumentar un poco si cabe, estas inquietudes, lo mismo por lo que en ella y en sus páginas de presentación aparece como por lo que en las mismas se va a echar en falta Moya Valgañon (1990, p. 18).

Con estas palabras el comisario de la exposición del Mueble español. Estrado y dormitorio, terminaba su introducción sobre la historiografía del mueble español en dicho catálogo. Exposición que, si ya fue importante por el elenco de autores encargados de redactar el catálogo, también lo fue por sus propias circunstancias, ya que vino a tomar el relevo expositivo que en Madrid se había iniciado con la de mobiliario español de los siglos XV y XVI y la primera mitad del siglo XVII, en 1912. Algo similar ocurrió en Cataluña donde la exposición El moble catalá, acontecida en 1994, puso de manifiesto la importancia y la repercusión tanto de la bibliografía sobre el mueble catalán, como la propia tradición catalana referente a la organización de exposiciones sobre muebles.

El mueble español. Estrado y dormitorio, tuvo lugar en Madrid en 1990, más de cien años después de que el Barón Davillier escribiese las breves referencias acerca del mobiliario español presente en la exposición parisina de 1879 (Davillier, 1879).Previamente, en 1872, Riaño había editado el catálogo de la reciente reorganización de las colecciones del South Kensington Museum, en el que Davillier tuvo a bien en inspirarse.

Estas exposiciones suponen el inicio de una serie de modelos de comunicaciones, mediante los cuales la Historia del Mueble Español ha encontrado varías vías por las que ha manifestado desde tendencias nacionalistas, hasta políticas y sociales, proyectando en cada una de ellas diversas realidades culturales.

\section{OBJETIVOS}

Aquí nos interesa establecer cuál fue el camino que llevó a tener la necesidad de realizar en Madrid, a fecha de 1990, una exposición monográfica que tuviese por objeto en exclusiva al mueble español, desde la Edad Media al siglo XIX incluido. Parece evidente que la exposición madrileña no solo fue el fruto de un caldo de cultivo que se inició a finales del siglo de la industrialización, sino que además abrió el camino a las futuras exposiciones de muebles, y siendo también el lugar que sirvió de punto de encuentro entre los principales teóricos de la historiografía moderna del mueble español.

El mueble, cualquiera que sea su patria de origen puede ser considerado desde multitud de puntos de vista, ya sea como una obra de arte, un producto cultural, un indicador de la industria y la economía de un lugar, o un referente sobre la posición 
social de aquellos que lo poseyeron. Dejando de lado todas estas consideraciones intelectuales sobre las que se puede abordar el estudio del mobiliario, un mueble ante todo es un volumen que ocupa un lugar en el espacio, por lo general bastante, y por ello susceptible a llenar "espacios" en exposiciones temporales. Los muebles, por lo general, son grandes, ocupan espacio y además son muy socorridos. No hay exposición que se preste que esté mínimamente relacionada con cuestiones sociales, históricas o artísticas, y ni que decir las monográficas brindadas a alguna personalidad destacada, donde no falta la mesa de despacho del homenajeado, con escribanía incluida, en las que no encontremos muebles, que habitualmente no suelen venir mucho a cuento. Estas exposiciones que contienen algunos muebles, no son las que aquí nos interesan. A lo largo del XX, son muchas las muestras que por algún motivo han tenido entre los fondos que exponían diferentes tipos de mobiliario. Así mismo ha sido parte inevitable y obligatoria en las diferentes exposiciones internacionales que en nuestro territorio se han venido desarrollando. Consideraremos aquí aquellas exposiciones relativas exclusivamente al mueble, aquellas en las que éste tuvo un peso importante por cuestiones numéricas o de repercusión social. En menor medida, citaremos algún ejemplo en el que la calidad y especificidad de los muebles en ella expuestos deban de ser obligatoriamente citados $^{2}$.

\section{METODOLOGÍA}

Con respecto a la metodología utilizada, se ha realizado un barrido bibliográfico e historiográfico del que se ha extraído todas y cada una de las referencias a cuantas exposiciones relacionadas con la historias del mueble se han celebrado en España desde los orígenes de su historiografía hasta principios del siglo XX. Una vez sistematizadas las mismas, se procedió con consultar uno por uno los catálogos de las mismas, analizándolos minuciosamente. Igualmente se reseñó todas y cada una de las noticas que la bibliografía especializada ha ido aportando lo largo del período objeto de estudio. En paralelo se procedió a consultar diferentes fuentes periodísticas con el objetivo de ampliar el imaginario social de cada una de las exposiciones y la repercusión mediática de las mismas.

\section{DISCUSIÓN. LAS EXPOSICIONES Y SU REPERCUSIÓN EN LA HISTORIA DEL MUEBLE ESPAÑOL. DIVERGENCIAS EN LOS MODELOS DE COMUNICACIÓN}

La cuestión de las exposiciones sobre muebles en España ha sido prácticamente olvidada por la historiografía española; algo difícil de entender ya que su origen está intrínsecamente relacionado al de la propia Historia del Mueble en España. Cuando en España se comenzaron a tener en cuenta nuestros muebles, allá por los años setenta del Ochocientos, hubo que mirar obligatoriamente a Londres, y a lo que allí se estaba haciendo de la mano de Juan Facundo Riaño. Casi en paralelo a los primeros trabajos que el citado autor comenzaba a editar para el South Kensington

\footnotetext{
${ }^{2}$ Moya Valgañón, en su historiografía del Mueble español. Estrado y dormitorio, recoge un buen número de estas exposiciones en las que se encuentran aportaciones de mobiliario. Es así mismo, casi exclusivamente el único teórico que presta atención en la bibliografía a la cuestión de las exposiciones dedicadas en exclusiva al mobiliario. Aporta también comentarios críticos sobre las mismas, a los que obligatoriamente aquí tendremos que hacer referencia.
} 
Museum como consecuencia de la reorganización de las colecciones de arte español que el museo custodiaba, se abría el camino hacia las exposiciones temporales de muebles españoles, abogando por la introducción de unos particulares lenguajes comunicativos, que permitirán asumir el discurso de lo que se estaba contando.

Podemos afirmar que, hasta 1990, las exhibiciones de muebles en España básicamente se realizaron entre Barcelona y Madrid, con igual número en la capital condal que en la del Reino, que sus orígenes están relacionados con las muestras que a nivel internacional se celebraron, y que solamente a partir de 1990 se observa una descentralización de las mismas, siendo acogidas por lugares como Santa Cruz de Tenerife, Valencia, Sabadell, Palma de Mallorca, Extremadura, Iniesta (Castilla la Mancha) o Girona. Las que fueron dedicadas exclusivamente a muebles comenzaron su andadura en 1912, y hasta 1990, prácticamente se celebraron apenas cuatro $^{3}$, de las cuales una se inauguró en Madrid, en 1912, y tres que tuvieron lugar en Barcelona, dos en $1923^{4}$ y una en 1979.

La década de los noventa en general supuso la llegada de nuevos aires a la historiografía del mueble en España, y un incremento considerable de las exposiciones de muebles, hasta cuatro, las dos citadas de Madrid y Barcelona, la que acogió Canarias sobre el mueble popular, y la que se celebró en Valencia con muebles del Museo Nacional de Cerámica y Artes Suntuarias, que tuvo lugar en la Feria de Anticuarios y Almonedistas de 1991.

Vamos a considerar las exposiciones seleccionadas en relación a cuatro grupos:

- Exposiciones relacionadas con los orígenes de la historiografía del mueble español. Comunicación histórica de los contenidos, y falta de rigor.

- Exposiciones celebradas en Madrid. Comunicación general de la Historia del Mueble español.

- Barcelona. Comunicación de caracteres nacionalistas.

- Otros lugares que han celebrado exposiciones de muebles. Asimilación de nuevas tendencias comunicativas.

\subsection{Una centralización bipolar. Madrid y Barcelona}

En 1879, el mismo año que tenía lugar la edición del libro de Miquel y Badia, con el simpático nombre Muebles y tapices. Segunda serie de cartas a una señorita sobre la habitación, tenía lugar en Paris una exposición sobre las Artes Decorativas españolas de la Edad Media y el Renacimiento que tuvo a bien editar un pequeño catálogo de 88 páginas. La obra en sí, o mejor dicho la exposición, nos interesa por ser una de las primeras muestras que recogen muebles españoles, cuyos textos están en relación con las obras de Riaño, permitiéndonos poder apreciar la rápida

\footnotetext{
${ }^{3}$ Los datos aquí presentados son siempre aproximados. Para su compilación se han tenido en cuenta las referencias localizadas por nosotros y aquellas propuestas por cuantos teóricos, artículos, monografías y catálogos de exposiciones que hemos podido consultar directamente.

${ }^{4}$ Este mismo año se editó el libro de MARTORELL, J., Interiors. Estructures autèntiques d'habitacion del segle XVIII al XIX. Exposició de Barcelona, Repertori iconografic, Barcelona, Seix Barral, 1923, que viene a ser un repertorio de imágenes de la exposición de Barcelona de 1923.
} 
difusión que los textos de Riaño para el South Kensington Museum tuvieron en otros países, según se expuso.

Poco después el español participó en el Catalogue of the Special Loan Exhibition of Spanish and Portuguese Ornamental Art. South kensington Museum, Londres, 1881, con el artículo "Essay of Spanish art". A año siguiente "casi todo lo presente en Londres se exhibió con varias piezas más en Lisboa en la Exposiçao retrospectiva de arte ornamental portugueza e hespanhola. Catálogo Ilustrado.

Madrid, a la vista del número de exposiciones de muebles que se han celebrado en Barcelona, presenta un notable descuelgue con respecto a ésta. Dedicadas en exclusiva al mueble español histórico, aquí tenemos constancia de dos ${ }^{5}$, la de 1990, y la celebrada en 1912, bajo el título Álbum de la Exposición de mobiliario español de los siglos XV y XVI y la primera mitad del siglo XVII, cuyo catálogo tuvo una segunda edición en $1918^{6}$. La segunda, promovida por la Sociedad Española de Amigos del Arte, supone un pequeño catálogo de apenas 18 páginas, y 32 planchas, dedicada a los muebles tardo-medievales y renacentistas españoles. Moya Valgañón, relaciona el escaso número de páginas del texto, y su edición como álbum, y no como catálogo, a los escasos conocimientos que hasta el momento se tenía sobre el mobiliario (Moya Valgañón, 1990, p. 13). El mismo año de la exposición, la Sociedad Española de Amigos del Arte editó un pequeño artículo sobre la misma y un inventario, textos que se incluirían en la citada edición de 1918. A diferencia de lo que pasará en España, las exposiciones que se celebran en Madrid, siempre tienen por objetivo comunicar una realidad lo más amplia posible, intentando ser reflejo de cuantos muebles se debieron realizar en el territorio nacional.

Con respecto a el Mueble español. Estrado y Dormitorio, ha tenido su singular importancia en la Historia del Mueble Español. Tuvo lugar entre septiembre y noviembre de 1990 en el Museo Español de Arte Contemporáneo, auspiciada por la Comunidad de Madrid. Los textos del catálogo fueron escritos por Rodríguez Bernis, Castellanos Ruiz, Aguiló y Junquera, los cuales además escribieron las fichas de los muebles en ella expuestos. La restauración de las obras expuestas, fue llevada a cabo por las Ordóñez, Cristina y Leticia, y María del Mart Rotaeche. Las dos primeras, posteriormente se unirían a la lista de teóricos del mueble español, especialmente en lo referente a las cuestiones relacionadas con la conservación de muebles, y son habituales colaboradoras en las obras colectivas actuales de Historia del Mueble español. El catálogo se estructuraba en una introducción que versaba sobre la historiografía del mueble español, cuatro

\footnotetext{
${ }^{5}$ No vamos a considerar en este trabajo las exposiciones que se han venido celebrándose sobre el mueble de diseño.

${ }^{6}$ Junquera Mato, J. J., 1999, p. 680. cita la exposición de 1918 como una nueva muestra, sin tener en cuenta que el texto de este año fue una segunda edición del catálogo de 1912, con el que comparte el mismo nombre. Este mismo autor, cita además las siguientes exposiciones: Catálogo de la exposición del Antiguo Madrid, Madrid, 1926; El modernismo en España, Casón del Buen Retiro, Madrid, 1969; Goya y el Infante don Luís de Borbón (Homenaje a la "Infanta" María Teresa de Vallabriga), Zaragoza 1996, y Diseño industrial en España, Museo Nacional Reina Sofía, 1998. Moya Valgañón, cita además, La heráldica en el arte, 1947; Carlos V y su ambiente, 1958; Velázquez y lo Velazqueño, 1960; El arte romántico, 1961; El Matrimonio de los Reyes Católicos, 1969. No consideramos aquí todos estos ejemplos, por contener casos aislados de muebles.
} 
capítulos dedicados a los muebles medievales, renacentistas, siglo XVII, siglos XVIII y XIX y un catálogo de obras con los estudios de las 99 piezas expuestas. La representatividad histórica de las piezas mostradas oscila entre la primera mitad del siglo XIV y 1870 aproximadamente. Entre las piezas expuestas cabría destacar la conocida popularmente como Alacena de Santa Úrsula, de la primera mitad del XV, y custodiada en el Instituto Valencia de don Juan; El sillón de los "Enríquez", del mismo museo; las sillas de caderas de la Catedral Primada de Toledo, granadinas de comienzos del siglo XVI; El sillón de las Bernardas Cistercienses de Alcalá de Henares; la Silla de brazos atribuida a Pedro de Ribera, o la espectacular cómoda de José Canops, del Patrimonio Nacional.

Desde el punto de vista de la comunicación y el impacto social que la misma tuvo, tanto el propio montaje como su catálogo, a día de hoy son consideras como paradigmáticas, ya que 25 años después sigue siendo uno de los libros de cabecera obligatorios de consulta.

Dentro de las exposiciones que han venido celebrándose en Madrid, queremos señalar la Exposición Histórico-Europea, 1892 a 1893, ya que en ella se expusieron parte de las colecciones del Conde de Valencia de don Juan, y que actualmente podemos contemplar en el Instituto que hoy día ocupa el que fue su palacio, y de don Guillermo de Osma (Mélida, J. R, 1898, pp. 363-376). Y Carlos IV. Mecenas y coleccionista (VV.AA., 2009). Obra imprescindible para conocer la asimilación y desarrollo del neoclasicismo en España, y su reflejo en las obras que aquí se crearon. La muestra estuvo planteada desde el punto de vista del coleccionismo y la protección de las artes por parte del monarca, donde los objetos en general y el mobiliario en particular jugaron un papel de vital importancia. Los muebles que se presentan en el catálogo probablemente estén entre los de mejor factura de cuantos se han podido realizar en la Península a lo largo de los siglos, siendo además el reflejo de la proyección de conjuntos armónicos e integrados.

Barcelona presenta un panorama totalmente contrario al expuesto de Madrid. EI número de exposiciones que se han realizado en esta zona, es síntoma del temprano interés que mostraron por sus propios muebles, su estudio y sistematización. Aunque las primeras exposiciones del mueble en España empezaron a realizarse en el año 1923, iniciaremos su aproximación comenzando por la Exposición Universal de Barcelona, que si bien queda excluida del grupo de las aquí propuestas, a nosotros nos interesa porque algunos de los muebles en ella expuestos, o mejor dicho, muebles de uso, han sido objeto de un particular estudio. Nos referimos al artículo editado en el número 8 de Estudio del Mueble, bajo el título Las vitrinas "internacionales" de los joyeros Masriera, escrito por la directora del Museu Frederic Marés, Pilar Vélez. Es interesante recoger la justificación que hace la autora para incluir este tipo de muebles como miembros de su propia historia:

Dentro de la gran familia del mueble, tan amplia y con tantas peculiaridades como las familias de carne y hueso, hay unos muebles primos lejanos que suman a la utilidad propia de numerosos elementos de mobiliario, en este caso, su función de contenedores, otro uso como expositores, una función también corriente en ciertas tipologías del mueble, pero con una dimensión especial: la de servir de escaparate público de uno objetos presentados en 
una exposición de cariz artístico-cultural, técnico, científico o, sencillamente, comercial (Vélez, 2008, p. 17).

Las vitrinas en sí, actualmente conservadas por Bagués-Masriera en la Casa Amatller del Paseo de Gracia de Barcelona, fueron las utilizadas por la casa Masriera Hermanos para presentar piezas de joyería y platería, apuntando la autora que pudieron ser diseñadas por Josep Vilaseca. La casa de joyería no solo ganó una medalla de oro, sino que por el propio diseño del stand y del mobiliario obtuvieron además el "premio único". He aquí un particular ejemplo de las posibilidades que ofrece la historia del mueble.

Avanzando en el tiempo, hasta 1923, encontramos que este año fue de singular importancia en la Historia del Mueble Español y del conocimiento de la decoración de interiores catalanes. Se editó el libro de Martorell, Interiors. Estructures auténtiques d'habitacions del segle XIII al XIX, y tuvieron lugar dos exposiciones sobre estas cuestiones, Exposición Internacional del Mueble y Decoración y L'amoblement $i$ els atuells de la casa antiga a Catalunya. Ambas muestras, que deberían haber sido complementarias, resultaron ser totalmente lo contrario: levantaron pasiones y críticas por igual. Moya Valgañón resalta el excesivo nacionalismo que se pretendió por parte de la Exposición Internacional del Mueble, y la puesta en escena de interiores falseados (Moya Valgañón, 1990, p. 15). Aquí hemos corroborado tales afirmaciones cotejándolas con la prensa de la época. En el ABC del 14 de febrero de 1923, se aluden a las intenciones de la muestra que se celebrará en la capital condal en mayo de ese mismo año. La muestra en sí se concibió como un "prólogo consolador para los que amamos a España y sentimos orgullos de su poderío de producción (...), tomando acuerdos importantes encaminados a asegurar la máxima fidelidad histórica de las instalaciones" (ABC, 14 de febrero de 1923). La exposición estaría compuesta de ocho habitaciones que comprenderían desde el arte gótico hasta el reinado de Isabel II. "La parte decorativa será reproducción de los interiores que se conservan, siendo amueblados con objetos auténticos, facilitados por los poseedores de los mismos"7. En la noticia también se alude a una de las reuniones celebradas para la gestión de la exposición, en la que participaron los funcionarios de la misma, Sres. Junyent, Golferich y Martorell, siendo probablemente este último el autor del texto anteriormente mencionado Interiors. Estructures auténtiques d'habitacions del segle XIII al XIX. Tales intenciones de veracidad histórica parece ser que quedaron sobre el papel, y teóricos como Torres Balbás levantaron el grito al cielo por lo inapropiado del diseño de la muestra: "daban escasa idea de lo que ha sido nuestro arte de la decoración doméstica" (Torres Balbás, 1925, pp. 189-196).

La Exposición Internacional del Mueble y Decoración de Interiores, celebrada en Barcelona en 1923 ilustra como pocas la dimensión social poliédrica de esta suerte de iniciativas en la Historia Contemporánea. En ella, el mueble no sólo aparecía como testimonio documental de los usos, modos y maneras, de las formas de vida y de las aspiraciones sociales de quienes lo poseen y hacen ostentación y uso visible del mismo, de cara a su propia afirmación "de clase". También la muestra sirvió a los

\footnotetext{
${ }^{7}$ Ídem.
} 
organizadores de "instrumento" de debate y aún de escaparate reivindicativo al pretenderse poner en valor los innegables y ya referidos valores identitarios y antropológicos del mueble como "producto" cultural de las sociedades, para trazar subliminalmente un imaginario itinerario propagandístico desde el catalanismo nacionalista/secesionista al vernáculo/españolista.

En consecuencia, la Exposición de 1923 se antoja decisiva al menos por cinco aspectos fundamentales para la Historia del Mueble y la visión del mismo: la conciliación del ámbito profesional con la vertiente pedagógica y educativa encauzada al conocimiento y los aspectos técnicos de su realidad material, el objetivo de aunar la competencia con la competitividad en el sector, promover la internacionalización y difusión de los industriales y diseñadores catalanes, apostar sin ambages por la modernidad como el parámetro que refrendase la funcionalidad y las garantías de confort brindadas por los productos ofrecidos $\mathrm{y}$, finalmente, la consagración del mobiliario histórico como referente de prestigio que refrenda el culto al pasado como sinónimo del esplendor y el orgullo nacionales.

La segunda de las muestras, que tuvo lugar en Barcelona en ese mismo año, tuvo mejor fortuna crítica que la anterior ${ }^{8}$. Desde 1923 , tenemos que saltar en el tiempo hasta 1979, cuando en la Sala d'Art Daedalus de Barcelona se realiza una pequeña muestra destinada al mobiliario del siglo XVIII, editando un pequeño catálogo de 72 páginas e ilustraciones, sobre la misma ${ }^{9}$, cuyo texto fue escrito por Mainar, bajo el título "Impromptu sobre el moble en el segle XVIII".

Bastante tiempo después, en 1994, se celebró la que probablemente ha sido la exhibición más importante realizada sobre mobiliario catalán. El moble catalá tuvo lugar en el Palau Robert del Paseo de Gracia barcelonés, la exposición, homenaje al Josep Mainar, contaba con 150 piezas que abarcaban desde la Edad Media a 1993, contando con manifestaciones del gótico, renacimiento, barroco, rococó, neoclasicismo, imperio, isabelino, fernandino, modernismo, Art Déco, funcionalismo o racionalismo, hasta el último diseño, incluyendo obras de Gaudí, Miró, Dalí y Tapies. A partir del Cuatrocientos, cada uno de los ocho periodos tuvo sus propios comisarios $^{10}$. La edición del catálogo contó un total de 428 páginas, número muy por encima de las 359 que presentaba en 1990 Estrado y Dormitorio, y unas cincuenta piezas más que el de Madrid. Mientras que el catálogo madrileño pretendía ser reflejo del mueble producido en España, el Moble catalá quería serlo de las obras más representativas de los territorios catalanes, extendiendo su contenido hasta la actualidad, mientras que la de Madrid, sólo mostró obras representativas hasta el ochocientos. En este sentido, El moble catalá, dio un giro de tuerca a las comunicaciones de la historia del mueble, ya que vino a trastocar las fronteras del mismo.

\footnotetext{
8 Moya Valgañón, citando de nuevo a Torres Balbás, afirma que, "La Junta de Museos monta en el de la Ciudadela una pequeña muestra de gran verismo, procurando el mayor rigor científico a la vez que didáctico, al acompañar de documentos escritos y reproducciones fotográficas de composiciones pictóricas antiguas de los objetos presentados" (Moya Valgañón, 1990, p. 20.)

${ }^{9}$ No hemos podido localizar quien fue el autor del catálogo, ni ninguna referencia a los muebles expuestos en el mismo.

${ }^{10}$ La Vanguardia, 19 de febrero de 1994, p. 33.
} 


\subsection{Nuevos focos de exposición}

Dentro de la geografía catalana aún, pero incluidas en el cuarto grupo de exposiciones que tuvieron lugar en otras áreas, queremos destacar otras cuatro exhibiciones que tuvieron lugar en Vilanova i la Gerltrú, Sabadell, Gerona y Torroella de Montgrí, la última de ellas en 2010.

En 1994, el museo Romántico Can Papiol, dedicó una pequeña muestra a la evolución de la silla catalana durante los siglos XVIII y XIX, donde se pudo apreciar el "modo de hacer" de Cataluña en lo relativo a las sillas (VV.AA., 1994).

En el año 2000, el Museu d'Art de Sabadell abrió al público una exposición titulada Estances privades. Mobiliari $i$ arts decoratives a Sabadell. 1830-1870, comisariada por Rosa María Creixell Cabeza, quien diez años después volvería a comisariar la reciente exposición de Torroella de Montgrí. La exhibición de Sabadell se articulaba en siete espacios, y pretendía reflejar el gusto por el mobiliario y las artes decorativas en Sabadell durante el periodo isabelino, partiendo del auge que la burguesía local tuvo gracias a la industria textil.

En 2006, Mónica Piera fue comisaria de la que sería su primera muestra individual, ya que en 1994, había formado parte del elenco de autores del Moble Catalá. El moble de lá Empordà al segle XVIII pasa a ser la primera exposición que en España se celebra sobre el mobiliario de una región en particular. Promovida y producida por la Fundación Caixa Girona, su catálogo contaba con 100 piezas de mobiliario producidas en esta zona a lo largo de Setecientos, y la introducción histórica al mueble de l'Empordá, realizada por la comisaria de muestra. La exposición y su catálogo además de ser el primer ejemplo del estudio del mobiliario particular de una región, nos interesa también por ser el germen de la magna obra que Piera Miquel editaría en 2008 bajo el título Audacia i Delicadesa. El Moble de Torroella de Montgrí i I'Ampordà (1700-1800), cuya edición fue promovida por la Fundación Moscort.

En esta Fundación, en 2010 tuvo lugar la última muestra que en España se ha producido sobre el mueble, Algunos muebles singulares. S. XV-XVIII. Se exhibieron sesenta muebles que destacaban por presentar alguna particularidad "todos estos muebles, podemos convenir, presentan alguna singularidad, intrínseca a su propia factura o adquirida con el paso del tiempo (...), aquello que convendremos en denominar el propio currículum del mueble, también se convierte en un rasgo importante de singularización en determinadas ocasiones" (Creixell I Cabeza, 2010: p. 13). Situados todavía en la antigua Corona de Aragón, en 1991, tuvo lugar con motivo de la Feria de Anticuarios y Almonedistas de Valencia una Exposición de muebles antiguos del Museo Nacional de Cerámica y Artes Santuarias "González Martí" y pinturas antiguas de colecciones particulares de Valencia, Siglos XVIII y XIX (Soler D'Hyver, 1991), donde se pudieron completar parte del patrimonio mobiliar conservado por esta institución. En Mallorca, desde el 2000 se han realizado dos exposiciones relacionadas con muebles, la primera en 2001, titula Mobles per a imatges. Escaparates, capelles $i$ campanes (segles XVII-XX), que tuvo como objeto el mobiliario destinado a la exposición de imágenes, y la celebrada en 2009, El moble a Mallorca. Segles XIII-XIX. Estat de la quesito. La historiografía del mueble mallorquín tuvo su gran momento con la edición, en 1994, del libro de Massot El 
moble a les illes Balears. Segles XIII y XIX, la principal y única obra de referencia sobre el mueble mallorquín hasta el momento. La exposición de 2009 , en cierta manera viene a completar las bases que se asentarón en la monografía citada. El catálogo de la muestra, comisariada por Kika Coll, colaboradora de la Revista Estudio del Mueble, cuenta con la participación de Margalida Bernat, Cristina y Leticia Ordóñez y Muí Morey entre otros.

Una de las últimas exposiciones a las que queremos hacer referencia es la que tuvo lugar en 1990 en el Museo de Antropología de Tenerife, que recibió por título El mueble popular en Canarias, y cuyo objeto de estudio fueron piezas estrechamente relacionadas con el campesinado. Es además la única exhibición que se ha destinado por completo al mueble popular.

En 2004, en Extremadura tuvo lugar una muestra itinerante "Proyecto mueble tradicional Extremeño", que venía a poner orden en el vació bibliográfico de esta región (VV.AA, 2004), y donde se exhibieron unas 70 piezas extremeñas de los siglos $\mathrm{XVI}$ al $\mathrm{XX}$.

La última de las exposiciones a la que nos queremos referir, tuvo lugar en 2010, en Iniesta (Cuenca), bajo el título "El mueble dorado y policromado de la Violla de Iniesta: una artesanía de Castilla-La Mancha (VV.AA., 2010) siendo de los pocos testimonios que podemos ofrecer sobre el mobiliario manchego.

La realidad de todas estas exposiciones pasan, por aportar nuevas posibilidades comunicativas en la historia del mueble, abogando en unos casos por las "micro narraciones locales", y en otros, por continuar con discursos anteriores, pero con el trabajo bien hecho y las intenciones de contar históricas verídicas documentales.

\section{CONCLUSIONES}

Queda de manifiesto como el interés por las exposiciones de muebles en España está intrínsecamente relacionado con los propios orígenes de la historiografía del mueble español, siendo partícipe de las muestras que sobre objetos españoles se produjeron en lugares como Londres, París o Lisboa. A partir de 1912, encontramos la primera muestra dedicada en España en exclusiva al mobiliario. Desde esta fecha han sido varias las exhibiciones que hemos podidos rastrear, principalmente celebradas en Madrid y Barcelona, ciudades a las que posteriormente hay que sumar las muestras realizadas en otros puntos de la geografía española. Dentro del conjunto total de las exposiciones que se han celebrado en España, tenemos que destacar dos, El mueble Español. Estrado y Dormitorio, y El moble catalá, celebradas en Madrid y Barcelona en 1990 y 1994 respectivamente. Y que por sus características y por el elenco de autores que escribieron en sus respectivos catálogos, una y otra, se han ganado un lugar propio dentro de la historiografía del mueble Español.

La visión del pasado que la Sección Retrospectiva nos ofrece es algo así como una enseñanza y una poesía. Enseñanza en cuanto revela el proceso de una industria y del arte, poesía en cuanto evoca los encantos de las edades pretéritas que son matices delicados de las páginas de la Historia (VV.AA., 1923). 


\section{REFERENCIAS}

ALMENAS (1912). La exposición de antiguo mobiliario español. Arte Español, 1, 5054.

CREIXELL I CABEZA, R. M. (2010). Alguns mobles singulars. Torroella de Montgrí: Fundació Mascort.

DAVILLIER, J. C. (1879). Les Arts Decoratifs en Espagne au Moyen Age et a la Renaissance. París.

JUNQUERA Y MATO, J. J. (1999). Muebles. Las artes decorativas en España en Summa Artis, XLV. Madrid: Espasa Calpe.

MARTORELL, J. (1923). Interiors. Estructures autèntiques d'habitacion del segle XVIII al XIX. Exposició de Barcelona, Repertori iconografic. Barcelona: Seix Barral.

MÉLIDA, J. R. (1893). Las colecciones del Sr. Conde de Valencia de don Juan y de D. Guillermo de Osma en la Exposición Histórico-Europea, en El Centenario, T. IV, 363-376.

MOYA VALGAÑÓN, J. G. (1990). Un siglo de Historiografía del mueble español, Mueble español. Estrado y Dormitorio. Madrid.

SOLER, D'HYVER, C. (1991). Exposición de muebles antiguos del Museo Nacional de Cerámica y Artes Suntuarias "González Marti” y pinturas antiguas de colecciones particulares de Valencia, Siglos XVIII y XIX. Valencia: Feria de Anticuarios y Almonedistas.

TORRES BALBÁS, L. (1923). Unas salas de la Exposición Internacional del Mueble y Decoración de Interiores en Barcelona en 1923, en Arquitectura, VII, pp. 189196.

VALVERDE (1912). Catálogo de la Exposición de mobiliario español de los siglos XV y XVI y primera mitad del siglo XVII, Arte Español, 1, 54-57.

VÉLEZ, P. (2008). "Las vitrinas "internacionales” de los joyeros Masriera”, en Estudio del mueble, 8, 17.

VV. AA. (1994). Adires dels degle XVIII i XIX a Catalunya. Catáleg de l'exposición. Vilanova i la Geltrú: Museu Romàntic Can Papiol.

VV. AA. (2009). Carlos IV. Mecenas y Coleccionista. Madrid: Patrimonio Nacional.

VV. AA. (2010). El mueble dorado y policromado de la Violla de Iniesta: una artesanía de Castilla-La Mancha, Catálogo de exposición. Iniesta, Cuenca: Ayuntamiento de Iniesta. 
VV. AA. (1923). Exposición Internacional del Mueble y Decoración de Interiores. Barcelona.

VV. AA. (2004). Proyecto mueble tradicional extremeño, Catálogo de Exposición. Extremadura: Instituto del corcho, la madera y el carbón vegetal. 